\title{
Studying the Efficiency of Endoscopic Method in Facial Fractures Treatment
}

\author{
Fathi HR ${ }^{1}$, Davudov MM${ }^{1,2 *}$ and Mammadov JJ ${ }^{2}$ \\ ${ }^{1}$ Department of Plastic, Reconstructive and Aesthetic Surgery, Iran \\ ${ }^{2}$ Department of Oral and Maxillofacial Surgery, Azerbaijan \\ *Corresponding author: Davudov MM, Department of Oral and Maxillofacial Surgery, Baku, Azerbaijan
}

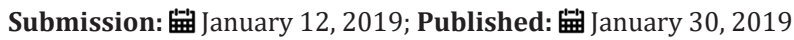

\begin{abstract}
Background: The current study headed to assess the safety and effectiveness of endoscopy in fractures of zygomatic arch, orbit and frontal sinus as well as sub condylar fractures to extend endoscopic approach in relevant surgeries in some referral centers over our country.

Methods: Through a clinical trial we evaluated three types of facial fractures in terms of their outcome, hardness and satisfactory rate when was corrected using endoscopy. Patients with frontal, zygomatic and orbital fractures who referred to Amir-Aalam and Vali-Asr hospitals in Tehran between October 2015 and September 2016 enrolled the study. Fractures of orbital base, isolated inverted fractures of the anterior table of frontal sinus, simple zygomatic fractures and fractures of mandibular condyle with insufficient occlusion were the cases to be recruited by the current study.

Result: The most common cause of fractures was accident (61.5\%) followed by falling (23.1\%), assault and sport trauma. All the cases with frontal fracture obtained good results (100\% rate) and orbit fractures were the next successful cases with $66.7 \%$ good results but zygomatic fracture had the most rate of fair outcome (60\%). Overall rate of good results was $64.7 \%$ whilst $35.3 \%$ fair response to endoscopic technique of surgery. Only one of the total fractures had a hard procedure, 12 (70\%) experienced easy procedure and $4(23.5 \%)$ moderate severity of surgery. Frontal cases reported the most rate of satisfaction (9.00) followed by orbit (8.11) and zygomatic (7.40) with no significant difference and surgeon was also satisfied mostly with frontal cases (8.67) and then orbit (8.11) and zygomatic ones (7.60).
\end{abstract}

Conclusion: The current trial confirmed the advantages of endoscopic approach in maxillofacial fractures chiefly due to perfect expose of the site of surgery. There was neither complication like ectropion, neural injury, and/or facial scars which one usually seen in transcutaneous approach.

Keywords: Facial fracture; Endoscopic approach; Frontal; Orbit; Zigoma; Difficulty; Satisfaction; Outcome

\section{Introduction}

Maxillofacial injuries are considered as one of the most important health difficulties in all over the world. Especially because it tends to appear highly and with various wastages [1-3]. In addition to these Maxillofacial fractures it accompanies with Severe morbidity, losing the function, deformity and significant cost [3-5]. Maxillofacial fractures mainly affect men [6-11] and have the highest incidence in the age range of 20-30 [7-9]. The maxillofacial fractures reasons are different among different population [9] and the most common causes in all over the world are traffic accidents, rape, falls, sport injuries and war [12-14]. Facial fracture treatments have been developed over the last century. Internal fixation with screws and plate (rigid internal fixation) has given us some tools for restoring the facial fractures with reduced morbidity more accurate [15]. In the last decade, alternative endoscopic approaches have been applied for restoring the facial fractures for achieving equal results to traditional approaches but with reduced morbidity (Figure1 \& 2). So, that endoscopy which access-minimal technique has limited using the cutting for creating exposer $[16,17]$.

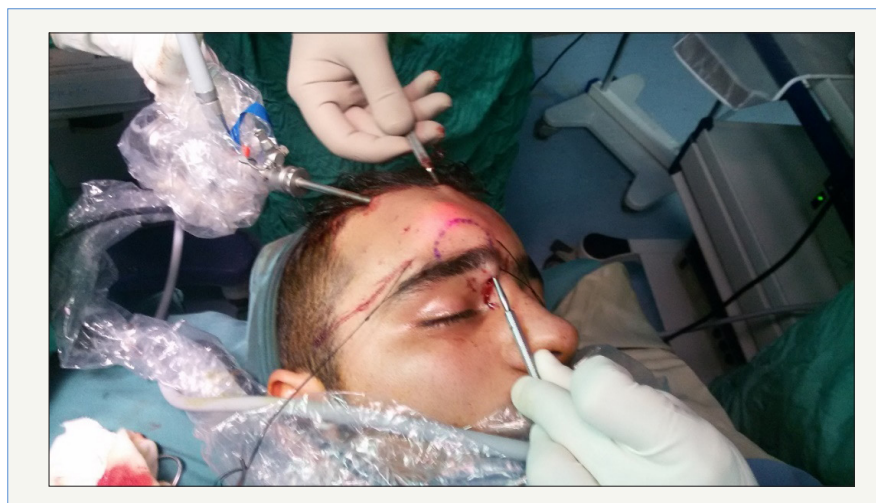

Figure 1: Frontal fracture endoscopic treatment.

\section{Material and Methods}

It's a case series study for those patients with facial fractures who presented to plastic surgery department of Vali-e-Asr hospital and Amir Alam hospital in 12 months (September 2015 to August 
2016). The eligible patients for the study have been informed for participating in study and treating by endoscopy. Before the surgery, CT-scan axial, coronal, sagittal and 3D was performed for all patients. Every patient with orbital fracture or vision problem has had an Ophthalmology Consultation. This consultation included Visual acuity, color vision, eye muscles examination, pupillary examination and evaluation of the optic nerve.

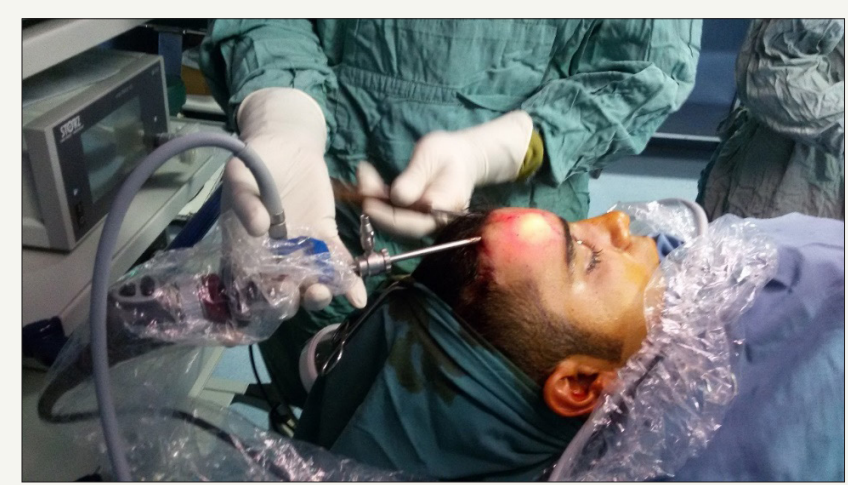

Figure 2: Frontal fracture endoscopic treatment.

\section{Inclusion criteria}

Orbital floor fractions, depressed isolated anterior frontal sinus fractures boards, zygomatic simple fractures, inability to achieve adequate occlusion of mandibular condyle fractures by closed reduction.

\section{Exclusion criteria}

Serious problem like any neurosurgical injury and vision problem, frontal sinus fractures linear and non-surgical indications anterior boards zygomatic complex fractures, wall fracture medial, lateral, orbital roof and mandibular fractures, patients with high internal fractures, fractures without displacement or fractures without loss of performance. The used endoscopic system was a Standard telescope $(4 \mathrm{~mm}, 30 \& 0$ degree). Endoscope was used for orbital floor fracture in order to control the reduction of orbital floor fractures and orbital tissue into eye socket. In the case of being a simple fracture (trap door), bone embedded in an anatomic position with overlapping edges. The reduction of bone fragments was kept in their place by the resistance between components. In the case of being a major defect and an unstable reduction fragments, a piece of proem was used to fill the defect. Forced duction test was done to ensure the free movement without bonding and moving parts for stable implant and then gingivobuccal incision was closed. For simple zygomatic arc fracture, an incision was done above the ear and behind the hairline. A periosteum elevator was used for dusky below the surface layer of deep temporal fascia in order to create an adequate vision and a 30-degree telescope with $4 \mathrm{~mm}$ piece was taken into and reduction of arc fracture was done using an elevator. Other zygomatic fractures were treated with traditional methods and intramural cutting. Small scalp incision is needed for Isolated anterior frontal sinus fractures boards. A direct dissection was done under the skin by endoscope (Table1). Then the 30 degree and $4 \mathrm{~mm}$ endoscope was used. It's possible to see the super orbital neuroscular and supra trochlear in hairy orbit. Sunken and broken parts have launched by elevator and have fixed using biologic glue. After completing the process, the frontal bone has washed and observed by endoscope, wounds or incisions have restored by (4-0) monocryl and (3-0) vicryl. Also, drain wasn't used and pressure dressing was applied (Table 2).

Table 1: The percentage of trauma causes.

\begin{tabular}{|c|c|c|}
\hline Cause of Trauma & Frequency & Percent \\
\hline Accident & 8 & 61.5 \\
\hline Assault & 1 & 7.7 \\
\hline Falling & 3 & 23.1 \\
\hline Sport trauma & 1 & 7.7 \\
\hline Total & 13 & 100 \\
\hline
\end{tabular}

Table 2: The relationship between type of fracture and result.

\begin{tabular}{|c|c|c|c|c|c|}
\hline & \multirow{2}{*}{\multicolumn{2}{|c|}{$\mathrm{P}=0 / 2$}} & \multicolumn{2}{|c|}{ Outcome } & \multirow{3}{*}{$\begin{array}{c}\text { Sum } \\
9\end{array}$} \\
\hline & & & \multirow{2}{*}{$\begin{array}{c}\text { Good } \\
6\end{array}$} & \multirow{2}{*}{$\begin{array}{c}\text { Fair } \\
3\end{array}$} & \\
\hline \multirow{6}{*}{ Study groups } & \multirow{2}{*}{ orbital } & Number & & & \\
\hline & & Percentage & $66 / 7 \%$ & $33 / 3 \%$ & $100 / 0 \%$ \\
\hline & \multirow{2}{*}{ zygomatic } & Number & 2 & 3 & 5 \\
\hline & & Percentage & $40 / 0 \%$ & $60 / 0 \%$ & $100 / 0 \%$ \\
\hline & \multirow{2}{*}{ frontal } & Number & 3 & 0 & 3 \\
\hline & & Percentage & $100 / 0 \%$ & $/ 0 \%$ & $100 / 0 \%$ \\
\hline \multirow{2}{*}{\multicolumn{2}{|c|}{ Sum }} & Number & 11 & 6 & 17 \\
\hline & & Percentage & $64 / 7 \%$ & $35 / 3 \%$ & $100 / 0 \%$ \\
\hline
\end{tabular}




\section{In condyle-mandibular fractures}

During this study, there was no eligible condyle-mandibular fractures for entering to the group.

1-10 post-surgery: During the post-surgery, first 5 days first generation cephalosporin was given to patients for preventing the infection. clinical and radiographic Post-operative examination was performed. CT-scan was performed 2 weeks after surgery on all patients. All patients were followed-up for 6 months after operation.

2-10 Consequences analyze: The group of variables which have been studied includes: age, gender, patient and doctor satisfaction index, side effects, the time elapsed between injury and surgery and hospitalization time. The results of endoscopic approach in terms of beauty and performance were classified into good, intermediate, weak. Good results include: return to the pre-injury condition (in terms of appearance and function) and without complications. Intermediate results include: inability to achieve to full terms of pre-injury, beauty and performance moderate satisfaction and some mild side effects that won't affect patient's performance. Also, the weak results include: complete inability to achieve the pre-injury functional-beauty conditions with the lass of satisfaction and side effects that mainly affects the function. Post-surgery patient and surgeon satisfaction index was considered by Visual An- alogue Scale (VAS). 1 to 10 considered in the questionnaire: 8-10 good, 5-7 moderate (average) and 1-4 weak. The surgical difficulty of the surgery was considered as easy, medium and hard according to the surgeon. Surgical methods were considered as Endoscopic approach (If surgery was done completely with endoscopic) and Endoscopic assisted technique (if surgery was done with help of endoscopy).

\section{Data analysis method}

First the questionnaire data was sheet coded to process by SPSS software. The $\mathrm{SD} \pm$ mean was used for quantitative variables and the percentage (\%) was used for qualitative variables. The significance level was considered less than 0.05. Parametric tests were used for normal distribution and non-parametric tests were used for non-normal distributions.

\section{Results}

In this study, 15 patients with facial fractures were examined which despite of repeated follow up, 2 patients were excluded from the study so, the data analyze was performed on 13 patients with 17 fractures. The mean age of subjects was 35/32 $\pm 95 / 13$ (Table 3). The youngest subject was 12 and the oldest was $57.92 .3 \%$ [12] of patients were man and 7.7\% [1] was a woman. This information is shown in Figure 3-5.

Table 3: The relationship between the difficulty degree of the surgery and the fracture type.

\begin{tabular}{|c|c|c|c|c|c|c|}
\hline & \multirow{2}{*}{\multicolumn{2}{|c|}{$P=0 / 3$}} & \multicolumn{3}{|c|}{ Surgical Difficulty Degree } & \multirow{2}{*}{ Sum } \\
\hline & & & \multirow{2}{*}{$\begin{array}{c}\text { Easy } \\
8 \\
\end{array}$} & \multirow{2}{*}{$\begin{array}{c}\text { Difficult } \\
0 \\
\end{array}$} & \multirow{2}{*}{$\begin{array}{c}\text { Average } \\
1 \\
\end{array}$} & \\
\hline \multirow{6}{*}{ Study group } & \multirow{2}{*}{ orbital } & Number & & & & 9 \\
\hline & & Percentage & $88 / 9 \%$ & $/ 0 \%$ & $11 / 1 \%$ & $100 / 0 \%$ \\
\hline & \multirow{2}{*}{ zygomatic } & Number & 2 & 1 & 2 & 5 \\
\hline & & Percentage & $40 / 0 \%$ & $20 / 0 \%$ & $40 / 0 \%$ & $100 / 0 \%$ \\
\hline & \multirow{2}{*}{ frontal } & Number & 2 & 0 & 1 & 3 \\
\hline & & Percentage & $66 / 7 \%$ & $/ 0 \%$ & $33 / 3 \%$ & $100 / 0 \%$ \\
\hline \multirow{2}{*}{\multicolumn{2}{|c|}{ Sum }} & Number & 12 & 1 & 4 & 17 \\
\hline & & Percentage & $70 / 6 \%$ & $5 / 9 \%$ & $23 / 5 \%$ & $100 / 0 \%$ \\
\hline
\end{tabular}

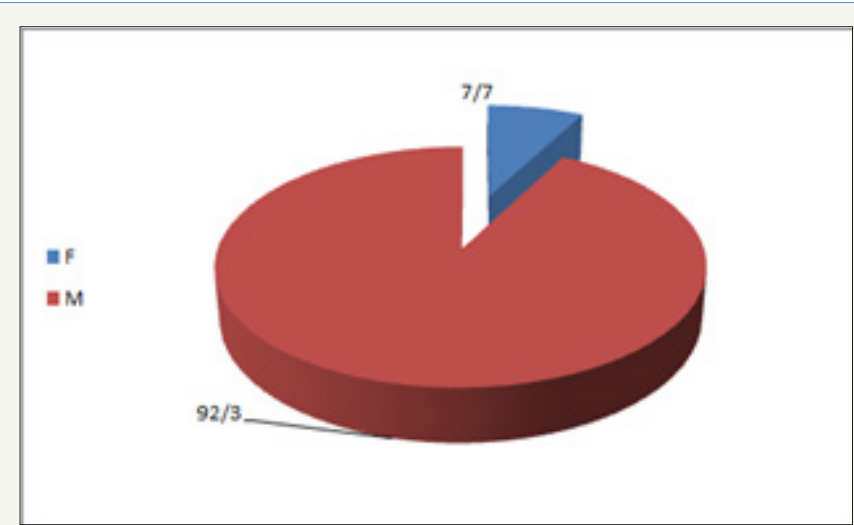

Figure 3: Gender distribution of patients.

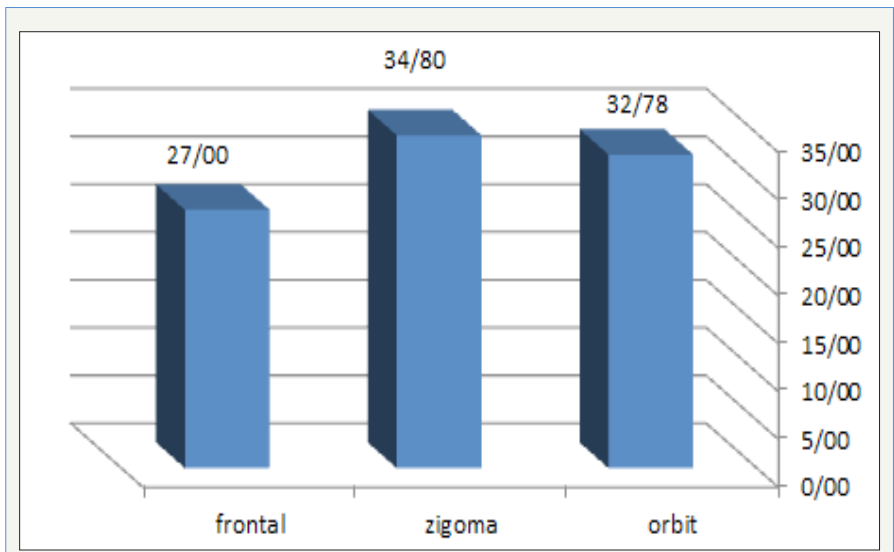

Figure 4: The age average of the fracture groups. 


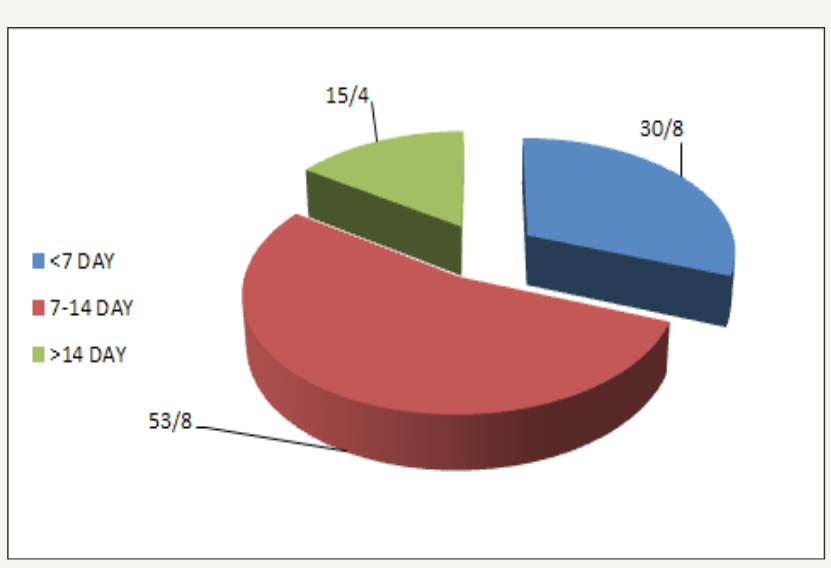

Figure 5: Time to trauma surgery.

\section{Discussion}

Using endoscopy in plastic surgery is the most recent development and its newest application is on maxillofacial fracture [1]. It has been reported that cranio-maxillofacial endoscopic is used in many facial fractures since 1994 [7]. In this study, there were 13 patients with 17 fractures that were eligible to enter the study (Table 4). 92.3\% were male and between the ages of 57-12 years with a mean of $35 / 32$ that coincides with the most relevant reports [18]. Trauma causes in our study in $61.5 \%$ was related to accident, 23.1\% Falling from height, 7.7\% sport injuries and 7.7\% dispute that was consistent with facial trauma etiology [18]. There has been a pre-surgery time for all patients to get ready and evaluate, some of them had some delay (maximum 20 days) to enter the study so, there was been an interval ( 4 to 20 days) with a mean of 9.6 days between trauma and surgery (Figure 6-8). We divided this period to 3 groups: to 7, 8-14 and more than 14 days, in order to evaluate the relationship between delay and difficulty of surgery and endoscopic surgery results. Endoscopic Approach (EAP) was used for bones reposition on all 9 patients with orbital fracture also, implant porex was used for 5 patients. Endoscopic Assisted was used for repositioning and fixing with screws and plates (ORIF) for all 5 patients with zygomatic fracture. EAP was used for resetting and fixing with Glue for patients with frontal fracture (3 patients) (without screws and plates) according to intraoperative findings.

Table 4: The relationship between fracture type and age, time to trauma surgery, patient and surgery satisfaction postsurgery hospitalization.

\begin{tabular}{|c|c|c|c|c|c|c|}
\hline \multicolumn{2}{|r|}{ Study Group } & \multirow{2}{*}{$\begin{array}{l}\text { Age } \\
0 / 8\end{array}$} & \multirow{2}{*}{$\begin{array}{c}\text { Time Between Trauma and } \\
\text { Surgery }\end{array}$} & \multirow{2}{*}{$\begin{array}{c}\begin{array}{c}\text { Patient satis- } \\
\text { faction }\end{array} \\
0 / 2\end{array}$} & \multirow{2}{*}{$\begin{array}{c}\begin{array}{c}\text { Post-Surgery Hospi- } \\
\text { talization }\end{array} \\
0 / 1\end{array}$} & \multirow{2}{*}{$\begin{array}{c}\begin{array}{c}\text { Surgeon Satis- } \\
\text { faction }\end{array} \\
0 / 3\end{array}$} \\
\hline & PVALUE & & & & & \\
\hline \multirow{2}{*}{ orbital } & Average & $32 / 78$ & $10 / 44$ & $8 / 11$ & $2 / 56$ & $8 / 11$ \\
\hline & Standard deviation & $15 / 39$ & $4 / 85$ & $1 / 27$ & $1 / 13$ & $1 / 05$ \\
\hline \multirow{2}{*}{$\begin{array}{l}\text { zygo- } \\
\text { matic }\end{array}$} & Average & $34 / 80$ & $11 / 40$ & $7 / 40$ & $2 / 60$ & $7 / 60$ \\
\hline & Standard deviation & $16 / 28$ & $6 / 54$ & $1 / 14$ & $0 / 89$ & $0 / 89$ \\
\hline \multirow{2}{*}{ frontal } & Average & $27 / 00$ & $9 / 00$ & $9 / 00$ & $1 / 33$ & $8 / 67$ \\
\hline & Standard deviation & $4 / 36$ & $2 / 64$ & $1 / 00$ & $0 / 58$ & $0 / 58$ \\
\hline \multirow{2}{*}{ sum } & Average & $32 / 35$ & $10 / 47$ & $8 / 06$ & $2 / 35$ & $8 / 06$ \\
\hline & Standard deviation & $13 / 95$ & $4 / 90$ & $1 / 25$ & $1 / 06$ & $0 / 97$ \\
\hline
\end{tabular}

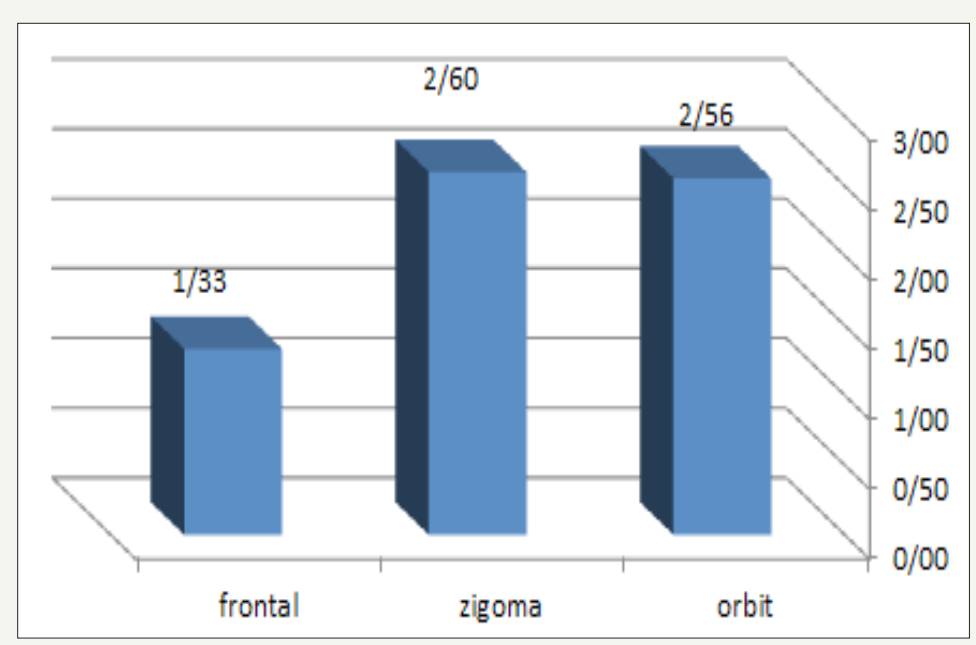

Figure 6: The post-surgery hospitalization, depending on the type of fracture. 


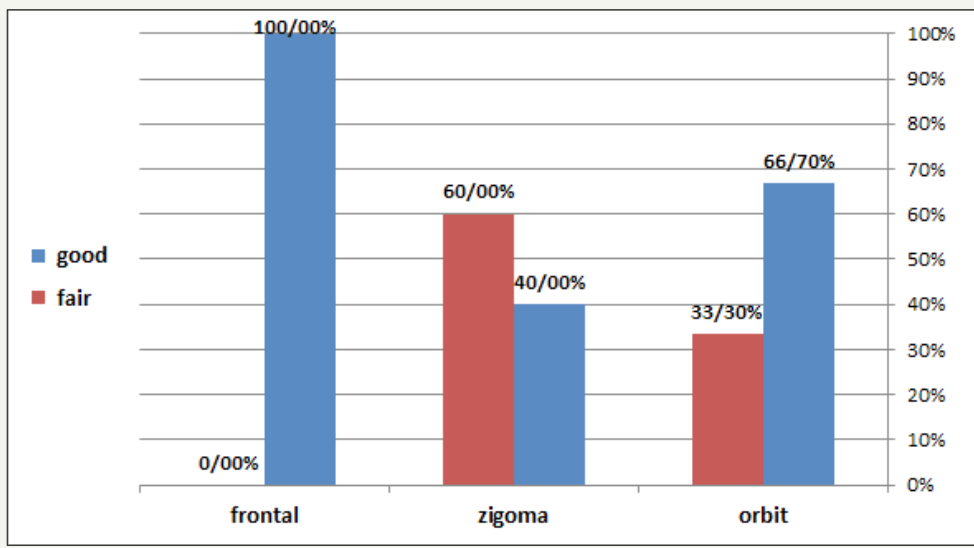

Figure 7: The relationship between type of fracture and result.

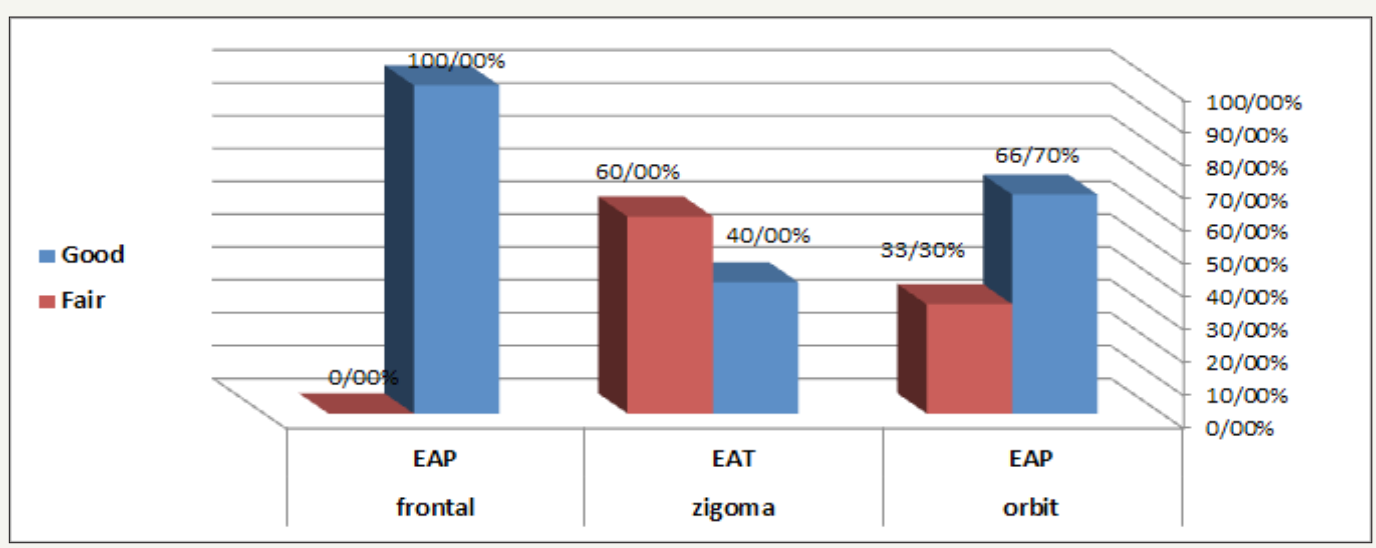

Figure 8: The relationship between surgery type and endoscopic approach.

The post-surgery hospitalization was 1-5 days (mean 2.35 days). It's an advantage in comparison to the hospitalization of traditional open surgery which takes $1-14$ days $[9,10]$. The advantage of fractures endoscopic repair has been reported in many studies [18]. We divided patients into three levels according to difficulty of surgery: easy, medium, difficult surgery. In this study, we had 12 easy, 4 medium and 1 difficult surgery. In patients with orbital fracture ( 9 patients) has been seen good results (return to pre-injury conditions in appearance and function) without side effects in $66.7 \%$ of patients and average results (lack of ability to return to pre-injury conditions with medium satisfaction and side effects that don't mainly affect the patient's beauty and function) has been seen in $33.3 \%$ of patients. The reason for having good results in orbital endoscopic surgery might be because of given great vision by endoscope from the orbital inferior and medial wall that allow to remove the bone fragments and fracture anatomic reduction safely. As this subject by other authors have also been reported [9]. The significant consequence in terms of exophthalmos and diplopia (side effect) has seen in orbital fracture patients, it seems to be a successful and careful treatment because of the orbital floor fracture repair under endoscopic control. These results are consistent with the results of other authors [13]. There were seen 2 good results and 3 average results in zygomatic patients ( 5 patients) (Figure 9-11). This average results might be because of their late refer- ral to the hospital and the surgery had been delayed 15-20 days and probably the union of the fracture fragments have been occurred. There were seen good results in all frontal fracture patients (3 patients). This good result might be because of early referral to the hospital and a great endoscopic sight and the absence of visible scar. When we observed the difficulty level of surgery in all three groups we've seen that the difficult surgery was seen in group of patients with zygomatic fracture (20\% difficult and $40 \%$ average) while the majority of surgeries in orbital group was easy (88.9\%). The frontal group was in the middle $(66.7 \%$ easy and $33.3 \%$ average). The reason might be due to the surgeon good visibility because of inherent space, the absence of trauma in adjacent bones, to sum up the stability of the orbital wall due to fixed points. On the other hand, the reason of the difficulty of surgery might be because of a long delay between trauma and surgery. It is also mentioned in other studies and pointed out that there is a direct relationship between the degree of difficulty and delay surgery [5]. The majority of difficult surgeries was in zygomatic fracture group in our study too and most people had late referral to hospital (Figure 12). This seems to be logical because fibrosis has formed between trauma to surgery time thus makes "Dissection" more difficult. Also, it has been mentioned that there is an inverse relationship between trauma to surgery time and surgery result [5]. 


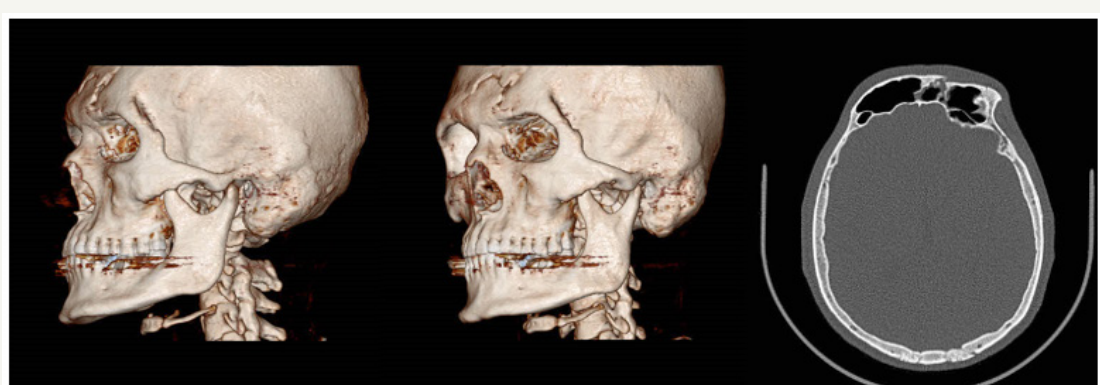

Figure 9: Pre-surgery CT scan of a patient with frontal fracture (Amir Alam Hospital).

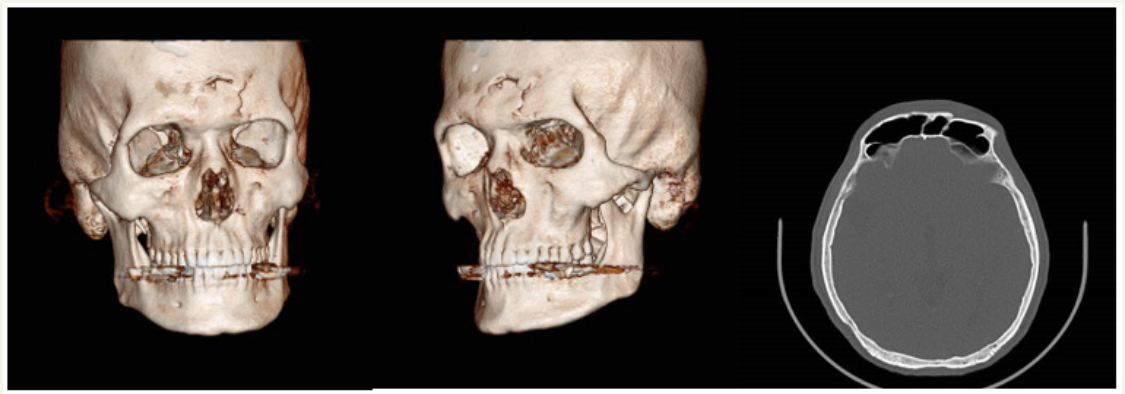

Figure 10: Pre-surgery CT scan of a patient with frontal fracture (Amir Alam Hospital).

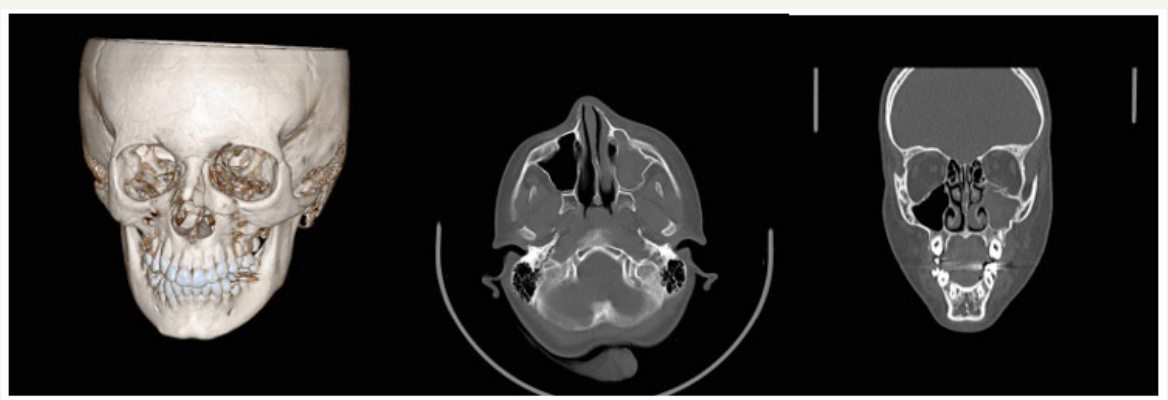

Figure 11: Pre- surgery CT scan of a patient with left orbital floor fracture and zygomatic (Amir Alam Hospital).

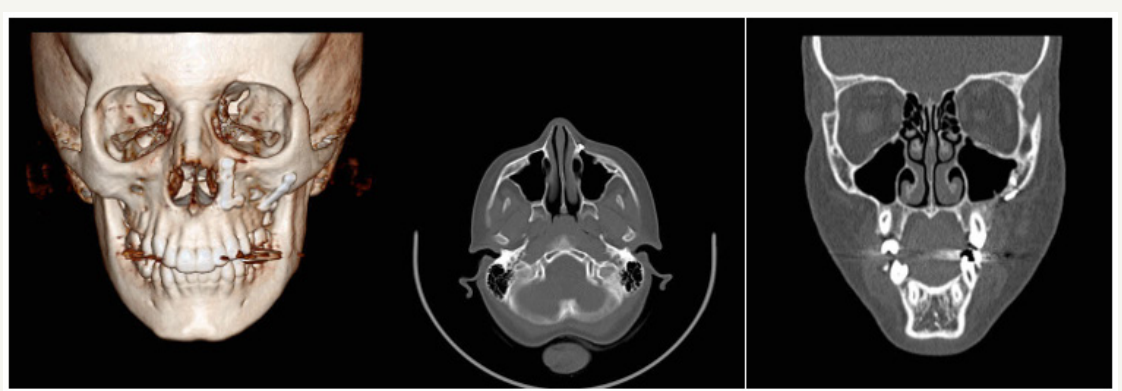

Figure 12: Post- surgery CT scan of a patient with left orbital floor fracture (Amir Alam Hospital).

Most average results were seen in patients with late referral to hospital. This relationship is convincible with the creation of fibrous tissue and memory caused in soft tissue with delay. In terms of endoscopic methods (EAP, EAT), the relationship between endoscopic approach and surgery result has been evaluated. There was no statistically significant relationship between them $(\mathrm{P}=0.5)$.
This relationship was not significant in other studies too [4]. We agree with other authors in terms of significant value of endoscopy in accurate expose and reduction of fracture in a three-dimensional view. Some of the benefits of endoscopic treatment in our study were clear: No post-operative complication associated with incision of trans-orbital such as ectropion or scars unpleasant in external 
approach can be seen there. A second endoscopic operation has done on an idealist patient with zygomatic fracture because of an average result and the second surgery data was considered in the study. Diagnosis and clear vision of edge of bones are possible by endoscopy so the reduction of implants is done safely with sufficient support.

\section{References}

1. Haug RH, Prather J, Indresano T (1990) An epidemiologic survey of facial fractures and concomitant injuries. J Oral Maxillofac Surg 48(9): 926-932.

2. Koorey AJ, Marshall SW, Treasure ET, Langley JD (1992) Incidence of facial fractures resulting in hospitalization in New Zealand from1979 to 1988. Int J Oral Maxillofac Surg 21(2): 77-79.

3. Down KE, Boot DA, Gorman DF (1995) Maxillofacial and associated injuries in severely traumatized patients: Implications of a regional survey. Int J Oral Maxillofac Surg 24(6): 409-412.

4. Qudah MA, Bataineh AB (2002) A retrospective study of selected oral and maxillofacial fractures in a group of Jordanian children. Oral Surg Oral Med Oral Pathol Oral Radiol Endod 94(3): 310-314.

5. Kieser J, Stephenson S, Liston PN, Tong DC, Langley JD (2002) Serious facial fractures in New Zealand from 1979 to 1998. Int J Oral Maxillofac Surg 31(2): 206-209

6. Kostakis G, Stathopoulos P, Dais P, Gkinis G, Igoumenakis D, et al. (2012) An epidemiologic analysis of 1,142 maxillofacial fractures and concomitant injuries. Oral Surg Oral Med Oral Pathol Oral Radiol 114(5 Suppl): S69-73.

7. Cabalag MS, Wasiak J, Andrew NE, Tang J, Kirby JC, et al. (2013) Epidemiology and management of maxillofacial fractures in an Australian trauma centre. J Plast Reconstr Aesthet Surg 67(2): 183-189.
8. Sasaki R, Ogiuchi H, Kumasaka A, Ando T, Nakamura K, et al. (2009) Analysis of the pattern of maxillofacial fracture by five departments in tokyo: A Review of 674 Cases. Oral Science International 6(1): 1-7.

9. Naveen SA, Naveen SV, Hegde N, Sharma, Prasad R (2012) The pattern of the maxillofacial fractures-A multicentre retrospective study. J Craniomaxillofac Surg 40(8): 675-679.

10. Kyrgidis A, Koloutsos G, Kommata A, Lazarides N, Antoniades K (2013) Incidence, aetiology, treatment outcome and complications of maxillofacial fractures. A retrospective study from Northern Greece. ] Craniomaxillofac Surg 41(7): 637-643.

11. Arangio P, Vellone V, Torre U, Calafati V, Capriotti M, Cascone P (2013) Maxillofacial fractures in the province of Latina, Lazio, Italy: Review of 400 injuries and 83 cases. J Craniomaxillofac Surg 42(5): 583-587.

12. Afzelius LE, Rosen C (1980) Facial fractures. A review of 368 cases. Int J Oral Surg 9(1): 25-32.

13. Motamedi MHK (2003) An assessment of maxillofacial fractures: A 5-year study of 237 patients. J Oral Maxillofac Surg 61(1): 61-64.

14. Ansari MH (2004) Maxillofacial fractures İn hamedan province, Iran: A retrospective study (1987-2001). J Craniomaxillofacial Surgery 32(1): 28-34.

15. Mueller R (2008) Endoscopic treatment of facial fractures. Facial Plast Surg 24(1): 78-91.

16. Perry M (2009) Maxillofacial trauma-developments, innovations and controversies. Injury 40(12): 1252-1259.

17. Chen CT, Lai JP, Chen YR, Tung TC, Chen ZC, et al. (2000) Application of endoscope in zygomatic fracture repair. Br J Plast Surg 53(2): 100-105.

18. Mohammad AMN, Rashad AH, Shreef EH, Khalil YA, Sheikh Y (2014) Assessment of endoscopic role in management of facial fractures. American Journal of Health Research 2(6): 392-396.
Creative Commons Attribution 4.0 International License

For possible submissions Click Here

\section{Submit Article}

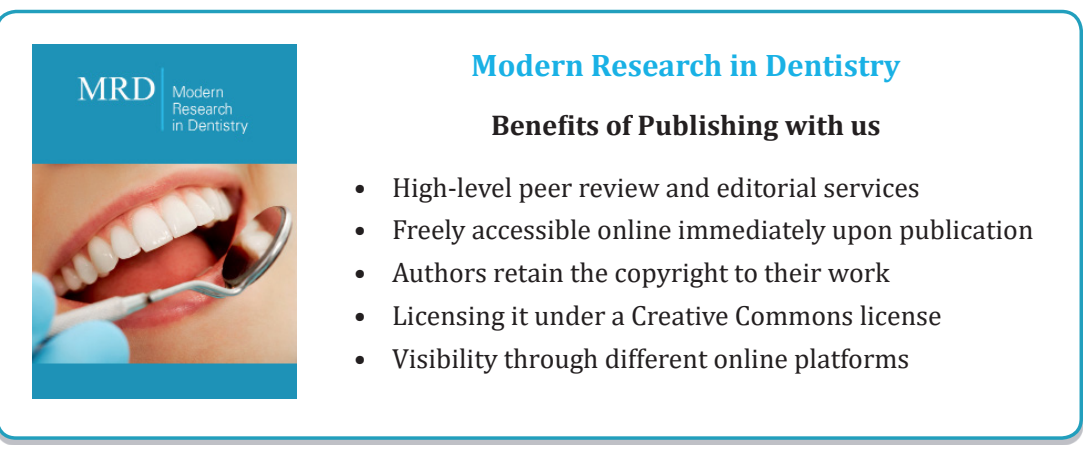

